\title{
Effects of grinding time on rheological, textural and physical properties of natural peanut butter stored at different temperatures
}

\begin{abstract}
The effects of ultrahigh speed grinding process duration of 2-4 min and its storage temperature on rheological, textural and physical properties of natural peanut butter produced from peanuts of Virginia and Spanish varieties were investigated. Both types of peanut butter samples exhibited food suspension with multimodal particle size distribution, fitted adequately to the Casson model and demonstrated nonNewtonian shear-thinning behavior with apparent yield stress. The storage $\left(G^{\prime}\right)$ and loss $\left(G^{\prime \prime}\right)$ modulus decreased as a function of grinding time and temperature. Grinding time and storage temperature gave significant effects on all the responses $(P<0.05)$ while peanut variety only has impact on the particle size distribution. Identical trends were observed for the natural peanut butter from both Virginia and Spanish peanut varieties.
\end{abstract}

Keyword: Feeding; Growth; Juveniles; Probarbus jullieni; Temoleh 